Journal of Animal and Veterinary Advances $10(5): 566-573,2011$

ISSN: $1680-5593$

(C) Medwell Journals, 2011

\title{
Response of Hepatic Metabolizing Enzymes and Oxidative Stress in Orally Administrated Zerumbone Against MIA-Induced Osteoarthritis in Rats
}

\author{
${ }^{1}$ F. J. Al-Saffar, ${ }^{1}$ S. Ganabadi, ${ }^{2}$ S. Fakurazi and ${ }^{3} \mathrm{H}$. Yaakub \\ ${ }^{1}$ Department of Preclinical Sciences, Faculty of Veterinary Medicine, \\ ${ }^{2}$ Department of Human Anatomy, Faculty of Medicine and Health Sciences, \\ ${ }^{3}$ Department of Animal Science, Faculty of Agriculture, \\ Universiti Putra Malaysia, 43400 Serdang, Selangor, Malaysia
}

\begin{abstract}
The main objective of this study was to elucidate the extent of hepatic oxidative stress following oral administration of zerumbone against monosodium iodoacetate induced Osteoarthritis (OA) in rats by monitoring microsomal cytochrome P450 and glutathione S-transferase enzymes as well as determination of oxidative stress biomarkers i.e., glutathione and malondialdehyde. Forty rats were randomly assigned into five groups. Rats in the first and second groups were treated with two different doses of zerumbone. Rats in the third group (positive control) were given celecoxib whereas the fourth group (negative control) was given corn oil. Rats of the fifth group were untreated not induced with $O A$ and were used as a basal group. Results showed significant induction of cytochrome P450 and glutathione S-transferase and insignificant changes in both glutathione and lipid peroxidation levels in zerumbone treated groups compared to corn oil and basal groups. Levels of ALT and AST in zerumbone treated groups were comparable to the level in the basal group indicating absence of liver damage. Prostaglandin $\mathrm{E}_{2}$ level significantly reduced following zerumbone administration. Safety profile of zerumbone in this study, attract new investigation to explore its advantageous effect on using higher dosage regimen and/or longer duration against $\mathrm{OA}$ or other disease.
\end{abstract}

Key words: Zerumbone, oxidative stress, cytochrome P450, glutathione, glutathione S-transferase, malondialdehyde

\section{INTRODUCTION}

The use of herbal natural products has gained interest among the world population so that many herbs have been developed into supplement which are claimed to reduce the disease symptoms and improve quality of life. Unfortunately, few adverse affect may be rise beside its pharmacological and therapeutic efficacy.

Apart from that zerumbone which is a crystalline sesquiterpene found in the rhizomes of the edible ginger known as Zingiber zerumbet Smith (Szabolcs et al., 2007). The underground rhizomes are the medicinally useful part (Ahmed et al., 2008) so that extensive studies were carried out through the last decade on their pungent constituents and among the pharmacological effects established were anti-inflammatory (Nharet-Somchit and Nur-Shukriah, 2003), anti-oxidants (Ruslay et al., 2007) anti-cancer (Yee et al., 2006) and anti-arthritic properties (Al-Saffar et al., 2010). Xenobiotics oxidative stress can influence the metabolism of cells in vital organs such as heart, nervous tissue and liver which is awfully hazardous as it does not exhibit any symptom and its identification is great difficult by means of laboratory methods (Kataria et al., 2010).

Xenobiotics such as drugs, chemical carcinogens, pesticides, environmental pollutants, ingested natural products and endogenous compounds are undergoing a number of hepatic and extra-hepatic enzymatic reactions referred to as biotransformation which may be categorized into phase I and phase II reactions (Hayes, 2008). Microsomal cytochrome P450s (CYP450) are an important phase I enzymes responsible for the metabolism of numerous xenobiotics.

Liver is the primary site of these enzymes. They render foreign compounds more water-soluble and thus facilitate their excretion (Nelson et al., 1996). Paradoxically, these enzymes may activate inert compounds as for example they can activates pro-

Corresponding Author: Shanthi Ganabadi, Department of Preclinical Sciences, Faculty of Veterinary Medicine, Universiti Putra Malaysia, 43400 Serdang, Selangor, Malaysia 
arcinogens to their ultimate carcinogenic form which is rendered suitable for interaction with nucleophilic sites in DNA (Koul et al., 2009). One of the most essential enzymes of phase II reactions are Glutathione S-Transferases (GSTs) which play an important role in both intracellular transport of hydrophobic molecules and the metabolism of toxic compounds (Zhu et al., 1998). The cytosolic GSTs which comprising over $95 \%$ of total cellular GSTs are the major isoforms involved in xenobiotics metabolism.

The cytosolic GST enzymes serve as ideal biomarkers and early indicators of organ damage which is applicable for both human and animals (Kilty et al., 1998). In essence, they catalyze the nucleophilic attack of the sulphur atom of GSH on the electrophilic group thus greatly decrease the reactivity of the compounds and make them more water soluble to favor their elimination (Sau et al., 2010).

Glutathione (GSH), a key master hepatic antioxidant biomarker is a superoxide radical scavenger where it protects thiol group required for maintaining the cell integrity against oxidation (Altinkaynak et al., 2003). It is an endogenous, non enzymatic antioxidant component present at highest concentration in the liver plays an important role in maintaining the intracellular redox equilibrium. It protects tissues from oxidative stress through glutathione peroxidase, glutathione reductase and the conjugation of intermediary metabolites through glutathione transferase (Jusman and Halim, 2009).

Glutathione conjugates have higher molecular weights and are more water soluble and more likely to be excreted in urine and bile than the parent compounds (Pompella et al., 2003). Malondialdehyde (MDA) is presumptive biomarker for lipid peroxidation which is enhanced in the presence of oxidative stress in the living organisms. Its elevation in various diseases thought to be related to the free radical damage so that its determination has been widely applied as the most common approach for the assessment of lipoperoxidation (Mateos et al., 2005).

There is paucity of research to detect oxidative stress associated with $\mathrm{OA}$ and its regulation with zerumbone. The study was designed to explore the effect of oral application of zerumbone on hepatic oxidative stress in the rat by monitoring important hepatic oxidative enzymes such as microsomal CYP 450, cytosolic GST and non enzymatic oxidative stress biomarkers i.e., GSH and MDA.

\section{MATERIALS AND METHODS}

Animals and induction of osteoarthritis: The study was performed on forty adult male Sprague Dawley rats each weighing approximately $275-400 \mathrm{~g}$ randomly assigned to five groups each of eight. The animals were obtained from the animal house facility and housed in well air-conditioned animal room at $22^{\circ} \mathrm{C}$ (one rat per cage). The rats were given commercial pellet and tap water ad libitum and were left for 2 weeks for acclimation before used.

The study was carried out according to the guideline for animal handling and care regulations and was approved by Animal Care and Use Committee (ACUC), Faculty of Veterinary Medicine, University Putra Malaysia (Reference: UPM FPV/PS/3.2.1.551/AUP-R44). To induce $\mathrm{OA}$, rats were anesthetized and injected intraarticularly with $50 \mu \mathrm{L}$ of MIA diluted with saline at a concentration of $60 \mathrm{mg} \mathrm{mL}^{-1}$ (Sigma, USA) in their right knee joints at day 0 (Bove et al., 2003).

Preparation of zerumbone and protocol of treatments: Zerumbone was prepared according to the method of Murakami et al. (1999). The preparation and qualification has been implemented at Analytical Laboratory and Quality Assurance Programmed Technical Services Centre, MARDI, P.O. Box 12301. General post office: 50774, Kuala Lumpur, Malaysia. Oral treatment was started at day 16 after $\mathrm{OA}$ induction and lasted for 4 weeks. Rats in the first (ZI) and second (ZII) groups were administered with $2 \mathrm{~mL} \mathrm{~kg}^{-1}$ body weight of $0.2 \%$ and $0.4 \mathrm{w} / \mathrm{v}$ zerumbone diluted in corn oil, respectively. Third group (CEL) were administered celecoxib (Celebrex ${ }^{\text {(a) }}$ ) at a dosage of $30 \mathrm{mg} \mathrm{kg}^{-1}$ body weight. Diluted in 5\% carboxyl methyl cellulose and served as positive control and rats in the fourth group were received Corn Oil (CO) at a dosage of $2 \mathrm{~mL} \mathrm{~kg}^{-1}$ body weight and served as negative control whereas rats of the fifth group were left untreated and without $\mathrm{OA}$ induction as a Basal (B) group.

Preparation of liver microsomal and cytosolic fractions: Rats were euthanized with intraperitoneal injection of $500 \mathrm{mg} \mathrm{kg}^{-1}$ sodium phenobarbital in line with current animal care regulations. Liver were excised and washed in cold $1.15 \% \mathrm{KCl}$ then mixed in 10 times to their weight with $1.15 \% \mathrm{KCl}$, minced well, homogenized thoroughly and centrifuged at $10^{4} \mathrm{~g}$ for $20 \mathrm{~min}$.

A volume of buffer A $[0.10 \mathrm{M}$ Tris-acetate buffer ( $\mathrm{pH} 7.4$ ) containing $0.10-\mathrm{M} \mathrm{KCl}, 1.0 \mathrm{mM}$ Ethylenediamine Tetraacetic Acid (EDTA) and $20 \mathrm{mM}$ Butylated Hydroxytoluene (BHT)] equal to the discarded sediment was added to the supernatant and centrifuged for $60 \mathrm{~min}$ at $10^{5} \mathrm{~g}$ (Beckman, XL-80 ultracentrifuge, 70.1 Ti rotor) to yield supernatant (contain the cytosolic fraction which was saved for subsequent uses) and a microsomal pellet. A volume of buffer B (0.10 M potassium pyrophosphate 
buffer ( $\mathrm{pH} 7.4$ ) containing 1.0 mMEDTA and $20 \mathrm{mMBHT}$ ) equal to that saved supernatant was added to the pellet and suspended, homogenized and recentrifuged at $10^{5} \mathrm{~g}$ for $60 \mathrm{~min}$. The resulted pellet was homogenized in $2 \mathrm{~mL}$ of buffer $\mathrm{C}(10 \mathrm{mM}$ Tris-acetate buffer ( $\mathrm{pH} 7.4)$ containing $1.0 \mathrm{mM}$ EDTA and $20 \%$ glycerol $(\mathrm{w} / \mathrm{v}))$ and stored at $-80^{\circ} \mathrm{C}$ (Hayes, 2008).

Determination of protein in liver: Unknown protein concentration in liver microsomal pellet, cytosolic fraction and homogenate was assayed using $\mathrm{BCA}^{\mathrm{TM}}$ protein assay kit (Thermo Scientific, USA) which was performed according to the manufacturer's instructions.

Determination of CYP P450: Aliquot from microsomal pellet was diluted with $0.05 \mathrm{M}$ PBS ( $\mathrm{pH}$ 7.4) to obtain sample contain protein concentration approximately $2 \mathrm{mg} \mathrm{mL} \mathrm{m}^{-1}$. Aliquot of $2 \mathrm{~mL}$ from this sample was transferred for each reference and sample cuvettes. Their baseline densities were determined using a spectrophotometer by scanning them from $420-490 \mathrm{~nm}$. Carbon monoxide was bubbled gently into the sample cuvette for $20 \mathrm{sec}$ then a small pinch of powdered sodium dithionite was added. The cuvette covered with a parafilm and inverted many times and then bubbled with carbon monoxide again for $20 \mathrm{sec}$.

The reference cuvette was treated only with a small pinch of sodium dithionite. The cuvettes were shaken vigorously then their observed densities were determined with the spectrum from $420-490 \mathrm{~nm}$. The quantity of CYP450 was calculated from the differences of optical densities and the molar extinction coefficient of $91 / \mathrm{mM} / \mathrm{cm}$ (Omura and Sato, 1964).

Determination of cytosolic GST activity: The procedure was conducted by the preparation of two cuvettes (sample and reference) each of $3 \mathrm{~mL}$ from the followings: $2.2 \mathrm{~mL}$ of $0.1 \mathrm{M}$ potassium phosphate buffer $(\mathrm{pH} 6.5$ ), $0.1 \mathrm{~mL}$ of $30 \mathrm{mM}$ CDNB substrate (1-chloro-2, 4dinitrobenzen from Aldrich Chemical Co.) and $0.1 \mathrm{~mL}$ of $30 \mathrm{mM}$ GSH. Both cuvettes were left for $1 \mathrm{~min}$ at room temperature $\left(25^{\circ} \mathrm{C}\right)$ and read with spectrophotometer at $340 \mathrm{~nm}$. An aliquot of $0.6 \mathrm{~mL}$ of the cytosol was added to the sample cuvette and mixed thoroughly. Reading was read after 1-5 min for both cuvettes at $340 \mathrm{~nm}$ with spectrophotometer. The specific activity of GST was expressed as nmol of GSH-CDNB conjugates formed $/ \mathrm{min} / \mathrm{mg}$ cytosolic protein using an extinction coefficient of $9.6 / \mathrm{mM} / \mathrm{cm}$ (Habig et al., 1974).

Determination of MDA: Upon euthanasia, livers were excised, weighed, washed and chilled in ice-cold $1.15 \%$
$\mathrm{KCl}$. Then $10 \%$ of liver homogenates in $1.15 \% \mathrm{KCl}(\mathrm{w} / \mathrm{v})$ were prepared and homogenized. Aliquot of $0.1 \mathrm{~mL}$ from the homogenate mixed with $0.2 \mathrm{~mL}$ of $8.1 \%$ sodium dodecyl sulfate, $1.5 \mathrm{~mL}$ of $20 \%$ acetic acid solution ( $\mathrm{pH} 3.5$ ) and $1.5 \mathrm{~mL}$ of $0.8 \%$ aqueous solution of thiobarbituric acid. The mixture was finally made up to $4.0 \mathrm{~mL}$ with distilled water and heated at $95^{\circ} \mathrm{C}$ for $60 \mathrm{~min}$.

After cooling with tap water, $1.0 \mathrm{~mL}$ of distilled water and $5.0 \mathrm{~mL}$ of $\mathrm{n}$-butanol were added and the mixture was shaken vigorously and centrifuged at $4000 \mathrm{rpm}$ for $10 \mathrm{~min}$, the upper butanol layer separated and read with spectrophotometer at $532 \mathrm{~nm}$ against pure n-butanol. The concentration of MDA was determined by comparison of absorbance to that of a standard curve with a range from 1-100 $\mu$ mols of authentic MDA (product of Sigma Co.) and

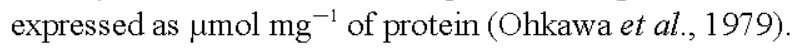

Determination of GSH: Total GSH concentration was measured in the liver homogenate according to the method of Sedlak and Lindsay described by Swarnakar et al. (2005). About $2 \mathrm{~mL}$ of $10 \%$ trichloacetic acid was added to a $2 \mathrm{~mL}$ of homogenate and centrifuged at $600 \mathrm{~g}$ for $15 \mathrm{~min}$. Then $2 \mathrm{~mL}$ of supernatant was added to $2.0 \mathrm{~mL}$ of $0.32 \mathrm{~mol} \mathrm{~L}^{-1} \mathrm{Na}_{2} \mathrm{HPO}_{4}$. About $5 \mathrm{~min}$ prior to the measurement of absorbance, $50 \mu \mathrm{L}$ aliquot of $0.01 \mathrm{~mol} \mathrm{~L}^{-1}$ Ellman's solution (5, 5-dithiobis-2nitrobenzoic acid) was added. The absorbance was determined at $412 \mathrm{~nm}$. The concentration of GSH was determined by comparison of absorbance to that of a standard curve with a range from 1-150 $\mu$ mols of authentic GSH (purchased from sigma chemicals Co.) and expressed

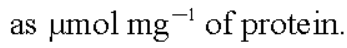

Measuring serum enzymes and prostaglandin $\mathbf{E}_{2}$ : Upon euthanasia $5 \mathrm{~mL}$ of blood was collected from all rats via cardiac puncture and left for $1 \mathrm{~h}$.

The blood was then centrifuged at $3000 \mathrm{rpm}$ for $10 \mathrm{~min}$ and then sera were collected and kept at $-20^{\circ} \mathrm{C}$ until use. Activity of ALT and AST were determined in units per liter using standard auto-analyzer methods (Automatic analyzer 902, Hitachi, Japan) and the kits (from Cobas Roche/Hitachi) used according to the manufacturer's protocol.

Determination of $\mathrm{PGE}_{2}$ was carried out using enzyme immunoassay kits (Assay Design purchased from USA, Catalog \#900-001) which was performed according to the manufacturer's protocol.

Statistical analysis: Statistical calculations were carried out with the SPSS 15.0 for Windows software package. Data was expressed as mean \pm SEM and analyzed with one way ANOVA and confirmed with student test (Table 1). 
Table 1: Hepatic concentrations of proteins, CYP450, GST, GSH and MDA in ZI (treated with $2 \mathrm{~mL} \mathrm{~kg}^{-1}$ body weight of $0.2 \%$ w/v zerumbone diluted in corn oil), ZII (treated with $2 \mathrm{~mL} \mathrm{~kg}{ }^{-1}$ body weight of $0.4 \% \mathrm{w} / \mathrm{v}$ zerumbone diluted in corn oil), CEL (treated with $30 \mathrm{mg} \mathrm{kg}^{-1}$ body weight diluted in $5 \%$ carboxyl methyl cellulose), CO (treated with $2 \mathrm{~mL} \mathrm{~kg}^{-1}$ body weight com oil) and B (left untreated) groups

\begin{tabular}{|c|c|c|c|c|c|}
\hline Concentration & ZI & ZII & CEL & $\mathrm{CO}$ & $\mathrm{B}$ \\
\hline Microsomal protein $\left(\mathrm{mg} \mathrm{g}^{-1}\right)$ wet tissue & $31.50 \pm 1.3$ & $31.55 \pm 0.90$ & $28.40 \pm 1.80$ & $31.52 \pm 1.90$ & $31.52 \pm 1.1$ \\
\hline Cytosolic protein $\left(\mathrm{mg} \mathrm{g}^{-1}\right)$ wet tissue1 & $164.59 \pm 3.5$ & $166.80 \pm 6.50$ & $143.67 \pm 3.809$ & $153.52 \pm 4.30$ & $164.68 \pm 2.6$ \\
\hline Homogenate protein $\left(\mathrm{mg} \mathrm{g}^{-1}\right)$ wet tissue & $189.10 \pm 4.2$ & $195.11 \pm 4.10$ & $159.07 \pm 2.40 \dagger$ & $185.95 \pm 3.60$ & $188.43 \pm 3.1$ \\
\hline Microsomal CYP450 $\left(\mathrm{nmol} \mathrm{mg}^{-1}\right)$ protein & $0.698 \pm 0.01^{*}$ & $0.701 \pm 0.02^{*}$ & $0.685 \pm 0.01^{*}$ & $0.582 \pm 0.03$ & $0.596 \pm 0.03$ \\
\hline Cytosolic GST (nmol/min/mg) protein & $1623.7 \pm 61^{* * *}$ & $1650.32 \pm 56^{\text {*** }}$ & $1223.4 \pm 73^{\text {***** }}$ & $1197.35 \pm 43$ & $1174.8 \pm 29$ \\
\hline Homogenate GSH $\left(\mu \mathrm{mol} \mathrm{g}{ }^{-1}\right)$ wet tissue \# & $3.7 \pm 0.17$ & $3.65 \pm 0.17$ & $3.74 \pm 0.09$ & $3.56 \pm 0.18$ & $3.47 \pm 0.15$ \\
\hline Homogenate MDA $\left(\mu \mathrm{mol} \mathrm{g}^{-1}\right)$ wet tissue \# & $6.72 \pm 0.2$ & $6.81 \pm 0.4$ & $6.82 \pm 0.35$ & $6.86 \pm 0.44$ & $6.77 \pm 0.3$ \\
\hline Serum ALT IU L ${ }^{-1}$ & $65.62 \pm 1.7 \pm$ & $62.32 \pm 0.9 \pm$ & $72.95 \pm 2.5 ¥$ & $85.02 \pm 4.9$ & $61.8 \pm 1.5 ¥$ \\
\hline Serum AST IU L ${ }^{-1}$ & $154.1 \pm 4.1 €$ & $149.5 \pm 3.1 €$ & $165.2 \pm 7.6 €$ & $200.6 \pm 14$ & $144.8 \pm 9.7 €$ \\
\hline 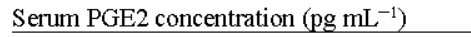 & $23317.5 \pm 713^{\mathrm{a}}$ & $19735.1 \pm 967^{\mathrm{a}}$ & $22845.1 \pm 750^{\mathrm{a}}$ & $34139.8 \pm 2404^{\mathrm{a}}$ & $17359.1 \pm 2123^{\mathrm{a}}$ \\
\hline
\end{tabular}

Data were analy zed using one-way ANOVA followed by student's t-test; All values were expressed as the mean \pm SEM ( $n=8$ ); $q$ Significantly $(\mathrm{p}<0.05$ ) lower versus ZI, ZII and B; † significantly $(\mathrm{p}<0.01)$ lowered versus other groups; * Significantly $(\mathrm{p}<0.05$ ) higher versus CO and B groups; ** Significantly ( $<0.01$ ) higher versus CEL, CO and B groups; ****Non significant difference ( $>0.05$ ) versus CO and B groups; \# No significant differences ( $>0.05$ ) between all

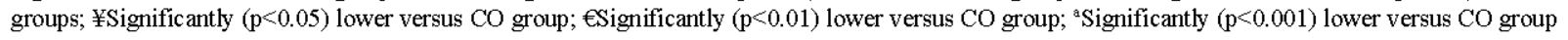

\section{RESULTS AND DISCUSSION}

All rats gained weight over the study period and there was no adverse effect following the treatments on body weight gain (Fig. 1). Protein assay in different preparations and enzymes content and activities as well as GSH and MDA levels in the liver tissues were well summarized and statistically analyzed as shown in Table 1. Assay of protein reveled non significant differences in microsomal pellet concentration between the groups.

While concentration of protein in both cytosolic fraction as well as liver homogenate revealed significant lowering in those of CEL group versus the others. Protein determined in the liver homogenate was higher than the cytosolic fraction and both were significantly higher than the microsomal pellets content. Microsomal content of CYP450 found significantly $(\mathrm{p}<0.05)$ induced in ZI, ZII and CEL groups compared with $\mathrm{CO}$ and $\mathrm{B}$ groups. Activity of cytosolic GST enzyme was induced significantly in Zerumbone treated groups (ZII, ZII). However, the activity of GST in rats treated with celecoxib was not significantly affected compared to $\mathrm{CO}$ or $\mathrm{B}$ groups. Determination of GSH in the liver homogenates of different groups revealed no significant elevation of its concentrations in ZI, ZII and CEL groups compared with $\mathrm{CO}$ and $\mathrm{B}$ groups. Whereas there was no significant changes in the level of MDA in ZI, ZII and CEL groups versus the levels found in both $\mathrm{CO}$ and $\mathrm{B}$ groups. The activity of ALT and AST showed no significant changes when compared to $\mathrm{CO}$ and $\mathrm{B}$ groups.

Assay of the inflammatory $\mathrm{PGE}_{2}$ showed a significant reduction of this hormone in the Zerumbone (ZI, ZII) and celecoxib treated groups compared to the negative control group (CO). Interestingly, $\mathrm{PGE}_{2}$ in ZII showed comparable level to that found in the B group. Recently, zerumbone was deliberated by the current team work for its effect on $O A$. Oral administration of zerumbone for a period

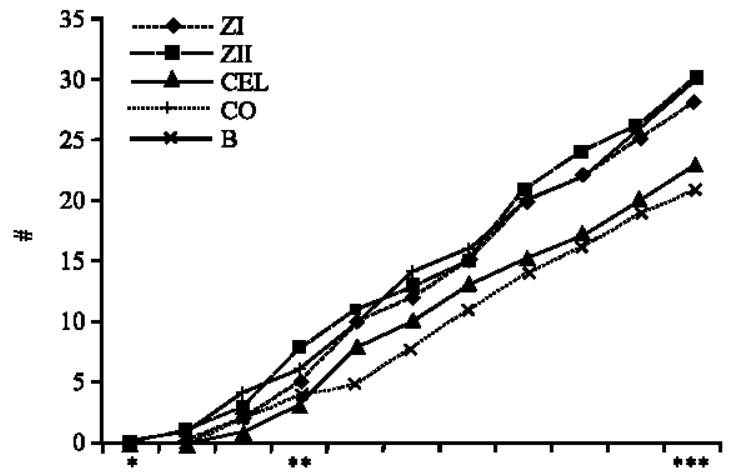

Fig. 1: The figure showed gradual gain (\#) in $g$ of the body weight in all groups throughout the experiment. The gain in zerumbone treated groups was comparable to the normal basal group (B). Body weight determined with 4 days interval in the ZI (treated with $2 \mathrm{~mL} \mathrm{~kg}^{-1}$ body weight of $0.2 \% \mathrm{w} / \mathrm{v}$ zerumbone diluted in corn oil), ZII (treated with $2 \mathrm{~mL} \mathrm{~kg}^{-1}$ body weight of $0.4 \% \mathrm{w} / \mathrm{v}$ zerumbone diluted in corn oil), CEL (treated with $30 \mathrm{mg} \mathrm{kg}^{-1}$ body weight diluted in $5 \%$ carboxyl methyl cellulose), $\mathrm{CO}$ (treated with $2 \mathrm{~mL} \mathrm{~kg}^{-1}$ body weight corn oil) and $\mathrm{B}$ (left untreated) groups. On day $0(*)$, OA was induced and lasted on day 15 $(* *)$ then followed with the treatment which was conducted till day $43(* * *)$

of 4 weeks revealed plausible chondroprotective effects on the knee OA in rats (Al-Saffar et al., 2010). The purpose of the current research is to explore the status of hepatic oxidative stress following zerumbone oral application to recommend longer course or higher dosage regimen of this natural remedy against $O A$ to obtain further anti-arthritic efficacy without any possible adverse effect.

Current data showed significant induction of CYP450 enzyme in zerumbone and celecoxib treated groups. The 
inducibility of the CYP450 enzyme system is an important property because it enables the organism to detoxify a wide range of exogenous compounds (Raza et al., 1998). Conversely, its reduction following malnutrition, cocaine administration or ether anesthesia will attenuate its metabolizing function (Vitcheva and Mitcheva, 2007). Without doubt, this enzyme is considered the prime metabolic route for the majority of xenobiotics, acting either directly in detoxification or indirectly by priming the xenobiotics for further metabolism (Hayes, 2008). The induction of this enzyme by the given dosage regimen and course of zerumbone in this investigation should be kept in consideration when supplemented with other drugs against $\mathrm{OA}$ and other diseases.

The premise is that drug interaction may occur and the inducibility may enhance the metabolism of these drugs or therapies which are substrates to CYP450 or some of its isozymes. Currently, induction of CYP450 by celecoxib also observed which is steady with previous findings (Koul et al., 2009).

Zerumbone possess activating properties towards phase II drug metabolizing enzymes (Murakami et al., 2004; Abdul et al., 2008). In the present research the activity of the hepatic cytosolic GST was induced significantly in Zerumbone treated groups (ZII, ZII) because of its potential inducibility to some of GST isozymes resulting in an induction of the total GST activity. Some of these isozymes being able to utilize major product of lipid peroxidation including fatty acid hydroperoxide and play a role in the protection against oxidative stress (Yang et al., 2001).

The enzyme conjugates the xenobiotics with glutathione (glutathionylation) producing metabolites which are more hydrophilic and are readily excreted in bile or urine as inactive conjugates. The induction of GST by zerumbone was parallel to the previous findings (Nakamura et al., 2004). The data showed no significant induction of GST activity by celecoxib which was comparable to the previous findings (Bastos-Pereira et al., 2010).

This enzyme is not the target of celecoxib activity in the oxidative stress process. Celecoxib failed to induce GST due to failure of further oxidation and $-\mathrm{COOH}$ formation (Sandberg et al., 2002). Currently, the levels of $\mathrm{GSH}$ and MDA biomarkers in the liver homogenates revealed no significant changes of GSH and MDA concentrations in ZI, ZII, CEL groups compared to both $\mathrm{CO}$ and $\mathrm{B}$ groups. Glutathione is a critical component of the oxidant defense system which helps in scavenging free radicals generated during poisoning. Currently, its level was not markedly different from the basal normal concentration indicating absence of free radical accumulation; otherwise its deficiency will signify an excessive production of reactive oxygen species (Sido et al., 1998). There is a strong correlation between MDA and GSH concentrations in the liver tissue because the oxidative stress leads to the formation of profuse reactive oxygen species which triggers the redox signaling cascade so that predispose to GSH depletion. As a response to these events, lipid peroxidation will be enhanced which is monitored by induction of MDA levels in the liver tissue (Jusman and Halim, 2009). Present findings revealed no depletion of $\mathrm{GSH}$ and no subsequent MDA induction in the rats treated with zerumbone.

It denotes that zerumbone exhibited antioxidant property by restoring the redox equilibrium (lipid peroxidation and GSH levels). Recently, it was found that zerumbone reduced the extent of liver damage caused by toxic agents as it can attenuate and prevent lipid peroxidation and preserved GSH antioxidant (Ibrahim et al., 2009).

Celecoxib and other NSAIDs showed no significant changes in the hepatic lipid peroxidation following its application compared to normal control animals (Karatopuk and Gokcimen, 2010; Bastos-Pereira et al., 2010). But they are capable to inhibit the elevated hepatic MDA in the oxidative stress in rats suffered hypercholesterolemia (Dabhi et al., 2008). El-Medany et al. (2005) found no significant change in GSH following oral administration of celecoxib in the normal wister rats but it can significantly decreases its level in the induced acetic acid colitis.

The determination of the activities of pathological enzymes like transaminases (ALT, AST) is a common means of detecting liver damage. Previously, ALT and AST enzymes considered as a marker of drug-associated hepatotoxicity (Brunner et al., 1998). However, the current data revealed no significant changes of ALT and AST activities following the treatment with the zerumbone or celecoxib.

Elevation of these enzymes due to the oxidative stress was well stated before (Modi et al., 2007; Fakurazi et al., 2008). Ibrahim et al. (2009) demonstrated an elevation of these enzymes in hepatic injury whereas he found that the pretreatment with zerumbone can prevents such changes. Also, previously found that celecoxib has no oxidative stress and toxic effect on these enzymes (Park et al., 2005).

Serum concentrations of $\mathrm{PGE}_{2}$ were inhibited significantly in zerumbone treated groups compared to $\mathrm{CO}$ group. Reduction of this hormone in the zerumbone treated groups was consistent with previous finding (Murakami et al., 2004). The data exposed a role of this 
hormone in OA events and following the treatment with zerumbone indicate zerumbone's anti-inflammatory property which was dose dependent. Interestingly, higher dose of zerumbone used in ZII group showed comparable level of this hormone to that of the basal group.

\section{CONCLUSION}

Current data showed that zerumbone with a given dose and duration course have significant inducible activity toward both CYP450 and Cytosolic GST enzymes, a property which is very important in biotransformation reactions of exogenous compounds.

Besides, zerumbone also exhibited antioxidant property by restoring the redox equilibrium because it restored the levels of hepatic GSH and MDA indicating absence of free radical accumulation and lipid peroxidation. Zerumbone does not have adverse effect on both ALT and AST as markers of damaged liver tissue.

Zerumbone anti-inflammatory activity was well stated by the inhibition of $\mathrm{PGE}_{2}$ following its application. Safety profile of zerumbone on the basis of this study, attract additional investigation to explore the advantageous effect of this herbal product on using higher dosage regimen and/or longer duration against $\mathrm{OA}$ or other disease.

\section{ACKNOWLEDGEMENTS}

The researcher wish to thank University Putra Malaysia as this study was supported by E-science grant (Project No.: 02-01-04-SF0882) awarded by Ministry of Science, Technology and Innovation. The researcher also wishes to thank Analytical Laboratory and Quality Assurance Programmed Technical Services Centre, MARDI, P.O. Box 12301. General post office: 50774, Kuala Lumpur, Malaysia.

\section{REFERENCES}

Abdul, A.B.H., A.S. Al-Zubairi, N.D. Tailan, S.I.A. Wahab, Z.N.M. Zain, S. Ruslay and M.M. Syam, 2008. Anticancer activity of natural compound (zerumbone) extracted from Zingiber zerumbet in human HeLa cervical cancer cells. Int. J. Pharmacol., 4: 160-168.

Ahmed, R.S., S.G. Suke, V. Seth, A. Chakraborti, A.K. Tripathi and B.D. Banerjee, 2008. Protective effects of dietary ginger (Zingiber officinales Rosc.) on lindane-induced oxidative stress in rats. Phytotherapy Res., 22: 902-906.
Al-Saffar, F.J., S. Ganabadi, S. Fakurazi, H. Yaakub and M. Lip, 2010. Chondroprotective effect of zerumbone on monosodium iodoacetate induced osteoarthritis in rats. J. Applied Sci., 10: 248-260.

Altinkaynak, K., H. Suleyman and F. Akcay, 2003. Effect of nimesulide, rofecoxib and celecoxib on gastric tissue glutathione level in rats with indomethacininduced gastric ulcerations. Polish J. Pharmacol, 55: 645-648.

Bastos-Pereira, A.L., D. Lugarini, A. Oliveira-Christoff, T.V. Avila and S. Teixeira et al., 2010. Celecoxib prevents tumor growth in an animal model by a COX-2 independent mechanism. Cancer Chemotherapy Pharmacol., 65: 267-276.

Bove, S.E., S.L. Calcaterra, R.M. Brooker, C.M. Huber and R.E. Guzman et al., 2003. Weight bearing as a measure of disease progression and efficacy of antiinflammatory compound in a model of monosodium iodoacetate-induced osteoarthritis. Osteoarthritis Cartilage, 11: 821-830.

Brunner, L.J., W.M. Bennet and D.R. Koop, 1998. Cyclosporine suppresses rat hepatic cytochrome P450 in a time-dependent manner. Kidney Int., 54: $216-223$.

Dabhi, J.K., J.K. Solanki and A. Mehta, 2008. Antiatherosclerotic activity of Ibuprofen, a nonselective COX inhibitor-An animal study. Indian J. Exp. Biol., 46: 476-481.

El-Medany, A., A. Mahguoub, A. Mustafa, M. Arafa and M. Morsi, 2005. The effects of selectivecyclooxygenases-2 inhibitors, celecoxib and rofecoxib, on experimental colitis induced by acetic acid in rats. Eur. J. Pharmacol., 507: 291-299.

Fakurazi, S., I. Hairuszah and U. Nanthini, 2008. Moringa oleifera lam prevents acetaminophen induced liver injury through restoration of glutathione level. Food Chem. Toxicol., 46: 2611-2615.

Habig, W.H., M.J. Pabst and W.B. Jakoby, 1974. Glutathione S-transferases. The first enzymatic step in mercapturic acid formation. J. Biol. Chem., 249: 7130-7139.

Hayes, A.W., 2008. Principles and Methods of Toxicology. 5th Edn., CRC/Taylor and Francis Group, USA., pp: 2270.

Ibrahim, M.Y., A.B. Abdul, S.I. Abdel Wahab, M.M. Elhassan, A.S. Alzubairi and M.M. Syam, 2009. Attenuation of cisplatin-induced hepatotoxicity in rats using zerumbone. Res. J. Biol. Sci., 4: 777-784.

Jusman, S.W.A. and S.A. Halim, 2009. Oxidative stress in liver tissue of rat induced by chronic systemic hypoxia. Makara Kesehatan, 13: 34-38. 
Karatopuk, D.U. and A. Gokcimen, 2010. Effect of tenoxicam on rat liver tissue. Turk. J. Gastroenterol., 21: 146-152.

Kataria, N., A.K. Kataria, R. Maan and A.K. Gahlot, 2010. Evaluation of oxidative stress in brucella infected cows. J. Stress Physiol. Biochem., 6: 19-25.

Kilty, C., S. Doyle, B. Hassett and F. Manning, 1998. Lutathione S-transferases as biomarkers of organ damage: Applications of rodent and canine GST enzyme immunoassays. Chemico-Biol. Interactions, 111-112: 123-135.

Koul, A., L. Tanwar and N. Arora, 2009. Celecoxib administration exhibits tissue Specific effect on $3 \mathrm{H}-$ benzo(a)pyrene-DNA adduct formation in cigarette smoke inhaling mice. Indian J. Exp. Biol., 47: 83-90.

Mateos, R., E. Lecumberri, S. Ramos, L. Goya and L. Bravo, 2005. Determination of Malondialdehyde (MDA) by high-performance liquid chromatography in serum and liver as a biomarker for oxidative stress application to a rat model for hypercholesterolemia and evaluation of the effect of diets rich in phenolic antioxidants from fruits. J. Chromatography B, 827: 76-82.

Modi, M., M. Mittal and S.J.S. Flora, 2007. Combined administration of selenium and meso-2.3dimercaptosuccinic acid on arsenic mobilization and tissue oxidative stress in chronic arsenic-exposed male rats. Indian J. Pharmacol., 39: 107-114.

Murakami, A., M. Takahashi, S. Jiwajinda, K. Koshimizu and H. Ohigashi, 1999. Identification of zerumbone in Zingiber zerumbet smith as a potent inhibitor of 12-O-tetradecanoylphorbol-13-acetate-induced epstien-barr virus activation. Biosci. Biotechnol. Biochem., 63: 1811-1812.

Murakami, A., T. Tanaka, J.Y. Lee, Y.J. Surh and H.W. Kim et al., 2004. Zerumbone, a sesquiterpene in subtropical ginger, suppresses skin tumor initiation and promotion stages in ICR mice. Int. J. Cancer, 110: 481-490.

Nakamura, Y., Y. Chiho, A. Murakami, H. Ohigashi and T. Osawa et al., 2004. Zerumbone, a tropical ginger sesquiterpene, activates phase II drug metabolizing enzymes. FEBS. Lett., 572: 245-250.

Nelson, D.R., L. Koymans, T. Kamataki, J.J. Stegeman and R. Feyereisen et al., 1996. P450 superfamily: Update on new sequences, gene mapping, accession numbers and nomenclature. Pharmacogenetics, 3: $1-42$.

Nharet-Somchit, N.M. and M.H. Nur-Shukriah, 2003. Anti-inflammatory property of ethanol and water extracts of Zingiber zerumbet. Indian J. Pharmacol., 35: 181-182.
Ohkawa, H., N. Ohishi and K. Yagi, 1979. Assay for lipid peroxides in animal tissues by thiobarbituric acid reaction. Anal. Biochem., 95: 351-358.

Omura, T. and R. Sato, 1964. The carbone monoxidebinding pigment of liver microsomes. J. Biol. Chem., 239: 2370-2378.

Park, K., J.H. Yang, Y. Choi, C. Lee, S. Y. Kim and Y. Byun, 2005. Chemoprevention of 4-NQO-induced oral carcinogenesis by co-administration of all-trans retinoic acid loaded microspheres and celecoxib. J. Controlled Release, 104: 167-179.

Pompella, A., A. Visvikis, A. Paolicchi, V. de Tata and A.F. Casini, 2003. The changing faces of glutathione, a cellular protagonist. Biochem. Pharmacol., 66: 1499-1503.

Raza, H., A. John, M.S. Lakhani, I. Ahmed and W. Montague, 1998. Multiplicity and tissue specific expression of camel Cytochrome P450(s). Comp. Biochem. Physiol. Part C, 121: 205-211.

Ruslay, S., F. Abas, K. Shaari, Z.M. Zainal and Maulidiani et al., 2007. Characterization of the components present in the active fractions of health gingers (Curcuma Xanthorrhiza and Zingiber zerumbet by HPLC-DAD ESIMS. Food Chem., 104: 1183-1191.

Sandberg, M., U. Yasar, P. Stromberg, J.O. Hoog and E. Eliasson, 2002. Oxidation of celecoxib by polymorphic cytochrome P450 2C9 and alcohol dehydrogenase. Br. J. Clin. Pharmacol., 54: 423-429.

Sau, A., F.P. Tregno, F. Valentino, G. Federici and A.M. Caccuri, 2010. Glutathione transferases and development of new principles to overcome drug resistance. Arch. Biochem. Biophys., 500: 116-122.

Sido, B., V. Hack, A. Hochlehner, H. Lipps, C. Herfarth and W. Droge, 1998. Impairment of intestinal glutathione synthesis in patients with inflammatory bowel disease. Gut, 42: 485-492.

Swarnakar, S., K. Ganguly, P. Kundu, A. Banerjee, P. Maity and A.V. Sharma, 2005. Curcumin regulates expression and activity of matrix metalloproteinases 9 and 2 during prevention and healing of indomethacin-induced gastric ulcer. J. Biol. Chem., 280: 9409-9415.

Szabolcs, A., L. Tiszlavicz, J. Kaszaki, A. Posa and A. Berko et al., 2007. Zerumbone exerts a beneficial effect on inflammatory parameters of cholecystokinin octapeptide-induced experimental pancreatitis but fails to improve histology. Pancreas, 35: 249-255. 
Vitcheva, V. and M. Mitcheva, 2007. Changes in liver and brain Cytochrome P450 after multiple cocaine administration, alone and in combination with nifedipine. Arh. Hig. Rada. Toksikol., 58: 287-291

Yang, Y., J.Z. Cheng, S.S. Singhal, M. Saini, U. Pandya, S. Awasthi and Y.C. Awasthi, 2001. Role of glutathione S-transferases in protection against lipid peroxidation: Overexpression of hGSTA2-2 IN K562 cells protects against hydrogen peroxide-induced apoptosis and inhibits Jnk and caspase 3 activation. J. Biol. Chem., 276: 19220-19230.
Yee, H.C., Z. Said, N. Hussien, A. Bustaman and N.H. Abdullah, 2006. Screening of chemically synthesized analogues of zerumbone for anti-cancer properties and in vivo investigation of zerumbone in female Balb/C mice with cervical intraepithelial neoplasm (CIN). BSc. Thesis, University of Putra, Malaysia.

Zhu, H.Z., X.L. Zhang and Y.S. Chen, 1998. Expression of glutathione S-transferase placental mRNA in hepatic preneoplastic lesions in rats. World J. Gastroenterol., 4: $38-40$. 